\title{
Ventilation during total intravenous anaesthesia with ketamine
}

Total intravenous anaesthesia with ketamine (TIVAK) is widely used throughout the world especially in precarious conditions. Although ketamine is usually considered to provide good respiratory function and may be used with spontaneous ventilation, recent studies have shown that desaturations may occur. Seventy-six adults and 64 children scheduled for peripheral surgery were randomly allocated to breathe spontaneously room air or $40 \%$ oxygen during TIVAK. Pulse oximetry was continuously assessed during anaesthesia and recovery. Desaturation $\left(\mathrm{SpO}_{2}<92 \%\right.$ ) occurred immediately after induction in 20 adults breathing air and in only three adults breathing oxygen $(P<0.05)$. Respiratory abnormalities were sufficiently severe to warrant tracheal intubation in two patients. Desaturations were not observed during the recovery period. Very similar results were observed in children although desaturations observed after induction in paediatric patients breathing room air were less frequent than in adults occurring in only nine patients. These desaturations were also less severe and never required tracheal intubation. The high incidence of arterial desaturation observed immediately after induction of anaesthesia with intravenous ketamine should prompt anaesthetists to provide oxygen in every adult patient at least for the first 15 min. The large decrease in $\mathrm{SpO}_{2}$ sometimes observed requires that trained personnel be present and that equipment for tracheal intubation be available.

L'anesthésie générale utilisant uniquement la kétamine par voie intraveineuse est très largement employée dans les pays en voie de développement ou en situation de guerre. Bien que la kétamine soit volontiers considérée comme associée à de bonnes

\section{Key words}

ANAESTHETICS, INTRAVENOUS: ketamine; ANAESTHESIA: developing world, paediatric; MEASUREMENT TECHNIQUES: pulse oximetry.

From the Malte Order Hospital*, Peshawar, Pakistan and the Department of Anaesthesia†, Hôpital Antoine Béclère, Clamart, France.

Address correspondence to: Dr. Dan Benhamou, Département d'Anesthésie-Réanimation Chirurgicale, Hôpital Antoine Béclère, 157, rue de la Porte de Trivaux, 92141

Clamart cedex, France.

Accepted for publication 6th November, 1993. conditions ventilatoires et permette le maintien de la ventilation spontanée, des études récentes rapportent la survenue de désaturations artérielles mises en évidence par l'emploi continu de l'oxymétrie pulsée. Soixante-seize adultes et 64 enfants ont été randomisés et ont reçu soit de l'air ambiant, soit une $\mathrm{FlO}_{2}$ de l'ordre de $40 \%$ au cours d'anesthésie intraveineuse à la kétamine en ventilation spontanée pour une chirurgie périphérique. $\mathrm{La} \mathrm{SpO}_{2}$ était mesurée en continu pendant l'anesthésie et le réveil. De nombreuses désaturations artérielles furent observées chez les adultes recevant de l'air immédiatement après l'induction anesthésique et deux patients durent être intubés en raison de la gravité des troubles respiratoires. Ces désaturations ne furent pas observées au cours du réveil chez ces mêmes patients. L'administration d'oxygène chez les adultes permit d'éviter la survenue de désaturation. Des résultats analogues furent enregistrés chez les enfants à la seule exception que les désaturations observées en l'absence d'administration d'oxygène furent moins nombreuses et moins profondes, ne nécessitant jamais dintubation trachéale. La grande fréquence des désaturations artérielles en oxygène observées immédiatement après lïnduction anesthésique doit imposer l'administration systématique d'oxygène chez les adultes anesthésiés avec la kétamine pendant au moins les quinze premières minutes de l'anesthésie. La sévérité parfois rencontrée de ces désaturations nécessite la présence de personnel entrainé et de matériel dintubation.

Total intravenous anaesthesia with ketamine (TIVAK) is widely used throughout the world especially in precarious hospital environments such as occur in war surgery. Total intravenous anaesthesia with ketamine is used in 30 to $50 \%$ of anaesthetic cases in the surgical programme of the Red Cross. ${ }^{1,2}$ There are many advantages to the use of ketamine in these circumstances. Moreover, such a simple anaesthetic technique may help local workers provide safe and effective anaesthesia.

Ketamine is usually considered to maintain good respiratory function and may be used with spontaneous ventilation. One recent study ${ }^{3}$ has shown, using continuous arterial oxygenation saturation $\left(\mathrm{SpO}_{2}\right)$, that minor and transient desaturation occurred in only $6 / 56$ adult patients breathing room air with TIVAK and scheduled for peripheral surgery. These respiratory abnormalities always occurred immediately after induction of anaesthesia and 
did not recur. By contrast, another study performed in similar conditions showed that severe $\left(\mathrm{SpO}_{2}<85 \%\right)$ desaturations were observed in $18 \%$ of adults breathing room air. ${ }^{4}$ Since our personal experience with TIVAK is more in agreement with those reports describing respiratory distress, ${ }^{4-7}$ we conducted this randomised study to examine (1) the incidence and the severity of desaturation during induction, maintenance and recovery from anaesthesia and recovery with TIVAK, and (2) the potential benefit of oxygen administration which has not been previously investigated separately. Since children represent a large part of this surgical population, the study was conducted in adults and in children.

\section{Methods}

The study was carried out between March and June 1992 at the Malte Order Hospital (French non-governmental organization) in Peshawar (Pakistan), capital of the North-West Frontier Province (altitude $500 \mathrm{~m}$ above sea level) where many Afghan refugee camps are located. The purpose of this surgical programme was to provide surgical facilities for civilian Afghan refugees and to train Afghan healthworkers. All ASA 1 or 2 patients scheduled for peripheral surgery without the use of muscle relaxants and with spontaneous ventilation were studied. Emergency patients and those presenting a contra-indication to ketamine (blood pressure $>160 / 90$, ischaemic heart disease, recent cranial or ocular trauma, abnormal psychiatric status) were excluded. Preanaesthetic assessment included age and weight determinations and a simple scoring of obesity where $0=$ thin patients, $1=$ normal, $2=$ mild obesity, $3=$ severe/morbid obesity. No premedication was given.

In the operating room, a venous cannula was inserted and isotonic sodium chloride was infused to maintain hydration. Before induction of anaesthesia, adult patients and children were separately randomized into two groups for the administration of oxygen or air. Groups 1 (adults) and 3 (children) breathed room air from arrival in the operating room until discharge from the recovery area. Group 2 (adults) and 4 (children) breathed a $40 \%$ oxygen-air mixture via a face mask. ${ }^{8}$ Anaesthesia was induced with $0.01 \mathrm{mg} \cdot \mathrm{kg}^{-1}$ atropine, $0.1 \mathrm{mg} \cdot \mathrm{kg}^{-1}$ diazepam and $2.5 \mathrm{mg} \cdot \mathrm{kg}^{-1}$ ketamine injected slowly over one minute. Boluses of ketamine $\left(1.25 \mathrm{mg} \cdot \mathrm{kg}^{-1}\right)$ were given as required during surgery. Spontaneous ventilation was maintained throughout the study. During anaesthesia and surgery, the patient's head was carefully positioned to maintain a patent airway. During recovery, the patients were placed in the lateral decubitus position and monitored for at least $\mathbf{4 5} \mathrm{min}$ before discharge. The time from induction of anaesthesia until incision was recorded. All patients were monitored continuously during anaesthesia and recovery with a digital pulse oximeter (Nellcor $100^{\circledR}$, France). The $\mathrm{SpO}_{2}$ was recorded while the patient was awake and breathing quietly, two minutes after induction of anaesthesia and then every five minutes until discharge. Any desaturation to $<92 \%$ was also recorded and treated immediately according to the suspected mechanism of desaturation. Central apnoea was treated by transient oxygen administration or by manual ventilation. When an obstructive pattern of ventilation was noticed, mandibular traction was applied and a Guedel airway was inserted. If these simple techniques failed to improve oxygenation, tracheal intubation was performed after succinylcholine administration.

Data for adult groups (Groups 1 and 2) and children (Groups 3 and 4) were considered separately for statistical analysis which included Student's $t$ test and two-way analysis of variance for quantitative data and chi square test for qualitative data. A $P$ value of $<0.05$ was considered significant.

\section{Results}

Seventy-six adults and 64 children were included in this study. In three children and one adult, $\mathrm{SpO}_{2}$ monitoring became unsatisfactory during recovery. Groups of adults and children respectively receiving (or not) oxygen did not differ for age, weight, obesity score, ketamine dosage to maintain anaesthesia and patient position during anaesthesia and surgery (Table Ia and Ib). Surgery began $6 \pm 3 \mathrm{~min}$ after induction of anaesthesia (NS between groups). Duration of surgery was longer in adults breathing room air (Table Ia). The type of surgery performed is shown in Table II. In adults breathing room air, there was a decrease in arterial oxygen saturation immediately after induction of anaesthesia compared with control $\mathrm{SpO}_{2}$ measured before anaesthesia (Figure 1). Desaturations were less frequent (air: 20/40 patients versus oxygen: $3 / 36$ patients, $P=0.001$ ) and less severe in adults receiving oxygen. Similar results were observed in children (Figure 2). However, the number of these desaturations was greater in adults (33\%) than in children (18\%) $(P=0.04)$ (Figure 3). Tracheal intubation as a treatment of severe desaturation was necessary in two adults because of apnoea associated with generalised rigidity (Figure 3). By contrast, tracheal intubation was never required in children. All the events occurred within a few minutes after induction of anaesthesia except in two children in whom hypersalivation caused respiratory obstruction during the course of surgery. No desaturation occurred during the recovery period.

\section{Discussion}

We found that TIVAK was associated with impairment of oxygenation especially in the $15 \mathrm{~min}$ following induc- 
TABLE Ia Characteristics of adult patients

\begin{tabular}{|c|c|c|c|}
\hline Adults & $\begin{array}{l}\text { Group I } \\
\text { without } \mathrm{O}_{2}\end{array}$ & $\begin{array}{l}\text { Group } 2 \\
\text { with } \mathrm{O}_{2}\end{array}$ & Statistics \\
\hline Age (yr) & $35.9 \pm 2.9$ & $29.6 \pm 2.0$ & NS \\
\hline Weight $(\mathrm{kg})$ & $59.5 \pm 2.0$ & $59.2 \pm 1.8$ & NS \\
\hline \multicolumn{4}{|l|}{ Obesity score } \\
\hline - Thin & 2 & 2 & NS \\
\hline - Normal & 31 & 32 & NS \\
\hline - Mild obesity & 2 & 5 & NS \\
\hline - Morbid obesity & 1 & 1 & NS \\
\hline Time (induction-incision) (min) & $6.0 \pm 3.1$ & $5.8 \pm 3.2$ & NS \\
\hline Duration of surgery (min) & $29.7 \pm 2.9$ & $39.7 \pm 3.7$ & $P<0.05$ \\
\hline Dose of ketamine during surgery $\left(\mu \mathrm{g} \cdot \mathrm{kg}^{-1} \cdot \mathrm{min}^{-1}\right)$ & $81.6 \pm 9.5$ & $66.7 \pm 4.1$ & NS \\
\hline \multicolumn{4}{|l|}{ Patients positions } \\
\hline - Dorsal decubitus $(n)$ & 39 & 32 & NS \\
\hline - Lateral decubitus (n) & 1 & 4 & NS \\
\hline
\end{tabular}

TABLE Ib Characteristics of paediatric patients

\begin{tabular}{llll}
\hline Children & $\begin{array}{l}\text { Group 3 } \\
\text { without } \mathrm{O}_{2}\end{array}$ & $\begin{array}{l}\text { Group 4 } \\
\text { with } \mathrm{O}_{2}\end{array}$ & Statistics \\
\hline Age (yr) & $8.1 \pm 0.6$ & $7.2 \pm 0.6$ & $\mathrm{NS}$ \\
Weight (kg) & $21.7 \pm 1.7$ & $20.9 \pm 1.6$ & $\mathrm{NS}$ \\
Obesity score & & & \\
- Thin & 2 & & $\mathrm{NS}$ \\
- Normal & 29 & 32 & $\mathrm{NS}$ \\
- Mild obesity & 1 & 0 & $\mathrm{NS}$ \\
- Morbid obesity & 1 & 1 & $\mathrm{NS}$ \\
Time (induction-incision) (min) & $5.7 \pm 3.3$ & $6.2 \pm 3.4$ & $\mathrm{NS}$ \\
Duration of surgery (min) & $33.7 \pm 2.7$ & $41.6 \pm 3.7$ & $\mathrm{NS}$ \\
Dose of ketamine during surgery $\left(\mu \mathrm{g} \cdot \mathrm{kg}^{-1} \cdot \mathrm{min}^{-1}\right)$ & $110.0 \pm 11.9$ & $92.8 \pm 4.0$ & $\mathrm{NS}$ \\
& & & \\
Patients positions & & & \\
- Dorsal decubitus $(n)$ & 30 & 31 & $\mathrm{NS}$ \\
- Lateral decubitus $(n)$ & 1 & 2 & $\mathrm{NS}$ \\
\hline
\end{tabular}

tion of anaesthesia. Most of these desaturations were prevented by oxygen administration. The desaturations were usually mild with no clinical consequence and disappeared spontaneously after a few minutes except in some adults in whom more severe desaturation requiring tracheal intubation was observed. Two adult patients with obesity scores of 2 and 3 respectively developed generalized muscle contracture with apnoea after injection of ketamine. Manual ventilation was impossible and because of severe desaturation (30 and $50 \%$ respectively) tracheal intubation was performed. This phenomenon has been described previously by Zsigmond et al., ${ }^{7}$ Morgan et al. ${ }^{9}$ and Jahangir. ${ }^{10}$ These data partially agree with those of Pesonen ${ }^{3}$ who showed that several patients had brief periods of desaturation. However, our interpretation of the data differs from that of Pesonen's who stated that "arterial oxygen saturation remained acceptable when patients breathed air during ketamine anaesthesia." We have found several severe desaturations and this is in agreement with Pederson who noted severe desaturations in adults with TIVAK and recommend that oxygen be available. ${ }^{4}$

Our study is the first to present a large group of children anaesthetised with TIVAK for surgical procedures and monitored with pulse oximetry. In other studies conducted in children, ketamine has been used for cardiac catheterisation or radiological procedures and ventilatory problems have also been described. In Malviya's experience of anaesthesia for interventional cardiology in children, the incidence of upper airway obstruction and hypercarbia was increased in patients receiving ketamine. 
TABLE II Types of surgery performed

\begin{tabular}{lcc}
\hline & Adults & Children \\
Type of surgery & $n=76$ & $n=64$ \\
\hline Orthopaedic & 27 & 6 \\
Plastic & 13 & 39 \\
Surgical dressing & 7 & 4 \\
Umbilical/inguinal hernia & 1 & 6 \\
Ganglion biopsy & 11 & 3 \\
Drainage of abscess & 7 & 4 \\
Haemorrhoidal surgery & 3 & 0 \\
Peripheral urology & 7 & 2 \\
\hline
\end{tabular}

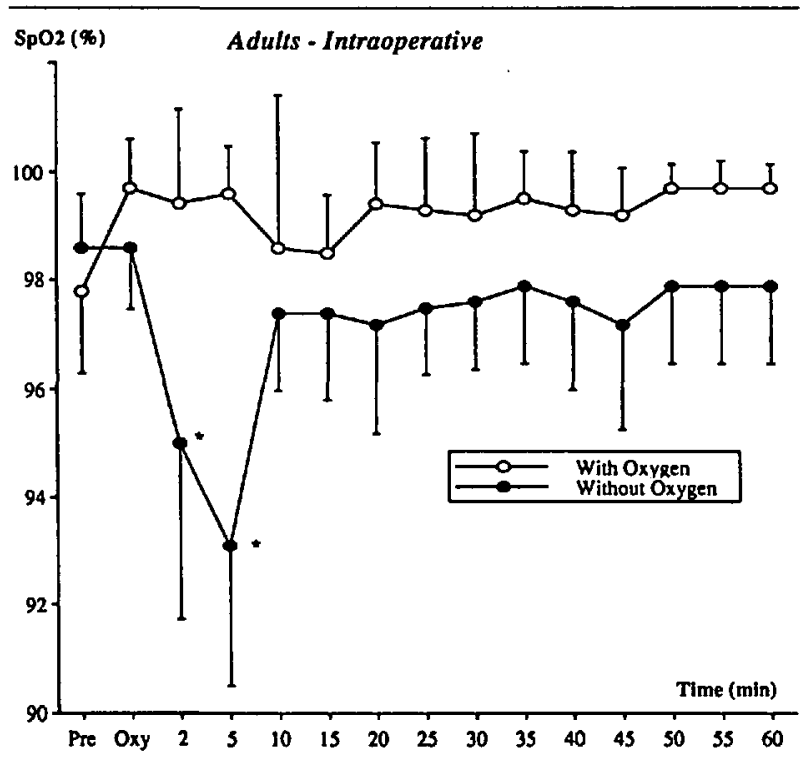

FIGURE 1 Evolution of arterial oxygen saturation $\left(\mathrm{SpO}_{2}\right)$ during anaesthesia and surgery in adult patients. Group 1 represents patients breathing room air ("without oxygen") and Group 2 represents patients receiving oxygen ("with oxygen"). $* P<0.05$ between groups.

Also, Hickey et al. ${ }^{6}$ used a similar technique for transcatheter closure of atrial septal defects and concluded that "although general anaesthesia with spontaneous ventilation using ketamine and midazolam was usually safe and effective, tracheal intubation for control of airway and ventilation was sometimes $(2 \%)$ necessary for safety and for optimal operating conditions." The high incidence of desaturation in our study may be explained by (1) the relatively large dose of ketamine necessary to perform surgical procedures (as opposed to non-surgical procedures), (2) the systematic use of diazepam which may have potentiated the respiratory depressant effect of ketamine, and (3) the continuous $\mathrm{SpO}_{2}$ monitoring which allowed any desaturation to be detected. The desaturation occurred immediately after induction of anaesthesia, i.e., at the time of the highest plasma ketamine concentration. The mechanism(s) of desaturation may be partly related

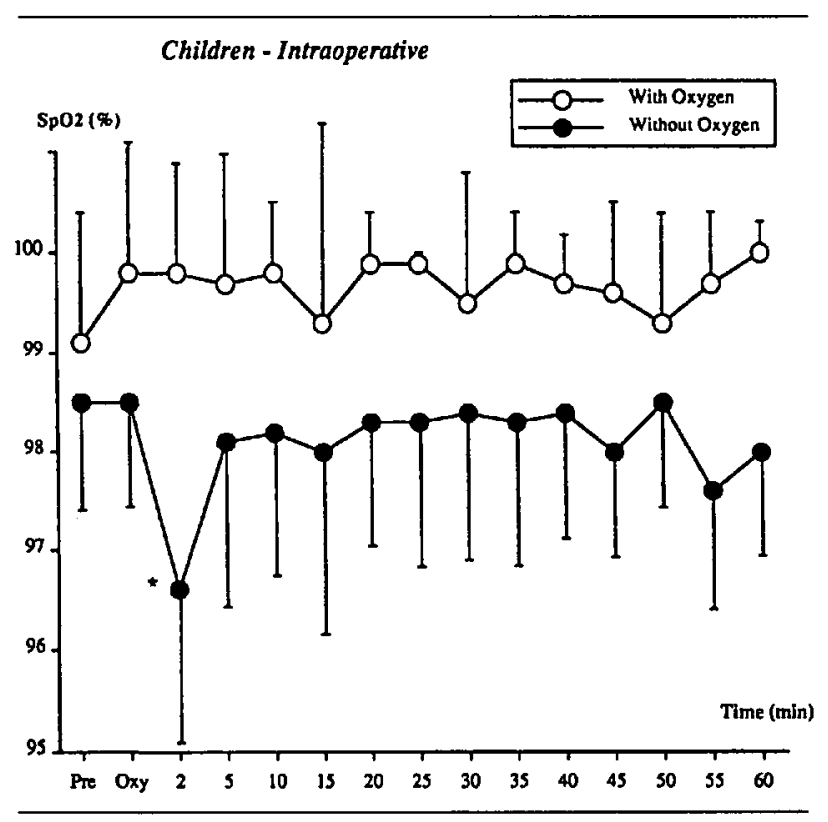

FIGURE 2 Evolution of arterial oxygen saturation $\left(\mathrm{SpO}_{2}\right)$ during anaesthesia and surgery in paediatric patients. Group 3 represents patients breathing room air ("without oxygen") and Group 4 represents patients receiving oxygen ("with oxygen"). ${ }^{*} P<0.05$ between groups.

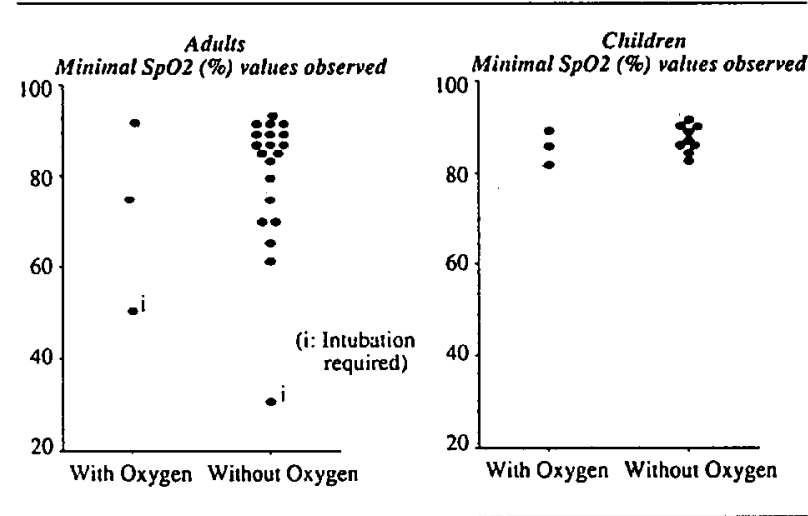

FIGURE 3 Minimal $\mathrm{SpO}_{2}$ values observed in adults and children during anaesthesia with ketamine. Each point represents the minimal value for one patient.

to airway obstruction but also to central ventilatory depression which is more pronounced when ketamine is used as a bolus. " Decreases in $\mathrm{SpO}_{2}$ were less frequent and less severe in children than in adults although ketamine doses (related to body weight) were larger than those used in adults. The larger requirement of ketamine in children agrees with previous reports ${ }^{12,13}$ and might be related to a decreased sensitivity to this drug in children. ${ }^{13}$

We chose a lower limit of $\mathrm{SpO}_{2}$ at $92 \%$ at which to commence treatment to improve oxygenation. This relatively high threshold was chosen for reasons of safety 
since a large number of children were included and may have contributed to the large number of desaturations recorded. Finally, the observer (LMJ) was not blinded to oxygen administration. However, our results probably remain unaffected by this bias in design since pulse oximetry provided an objective assessment of arterial oxygen saturation.

\section{Conclusion}

Although total intravenous anaesthesia with ketamine is a useful technique, its reputation of respiratory safety needs to be reconsidered. Desaturation occurred especially in adult patients whereas it was less intense and less frequent in children. The high incidence of arterial desaturation observed immediately after induction of anaesthesia should encourage anaesthetists to provide oxygen administration in every patient at least for the first $15 \mathrm{~min}$ after its administration. The large decrease in $\mathrm{SpO}_{2}$ sometimes observed requires that trained personnel be present and that equipment for tracheal intubation be available.

\section{Acknowledgement}

The authors gratefully acknowledge NELLCOR ${ }^{\circledR}$ France which provided the two pulse oximeters used in this study.

\section{References}

1 Trouwborst A, Weber BK, Dufour D. Medical statistics of battlefield casualties. Injury 1987; 18: 96-9.

2 Lenz $G$, Stehle $R$. Anesthesia under field conditions. A review of 945 cases. Acta Anaesthesiol Scand 1984; 28: 351-6.

3 Pesonen MD. Pulse oximetry during ketamine anaesthesia in war conditions. Can J Anaesth 1991; 38: 592-4.

4 Pederson $L$, Benumof $J$. Incidence and magnitude of hypoxaemia with ketamine in rural African hospital. Anaesthesia 1993; 48: 67-9.

5 Malviya S, Burrows FA, Johnston AE, Benson $L N$. Anaesthetic experience with paediatric interventional cardiology. Can J Anaesth 1989; 36: 320-4.

6 Hickey PR, Wessel DL, Streitz $S L$, et al. Transcatheter closure of atrial septal defects: hemodynamic complications and anesthetic management. Anesth Analg 1992; 74: 44-50.

7 Zsigmond EK, Matsuki A, Kothary SP, Jallad M. Arterial hypoxemia caused by intravenous ketamine. Anesth Analg 1976; 55: 311-4.

8 Fairfield JE, Goroszeniuk T, Tully AM, Adams AP. Oxygen delivery systems - a comparison of two devices. Anaesthesia 1991; 46: 135-8.

9 Morgan $M$, Loh $L$, Singer $L$, Moore PH. Ketamine as the sole anaesthetic agent for minor surgical procedures. Anaesthesia 1971; 26: 158-65.
10 Jahangir SM, Rahman $K$. Prolonged apnoea, trismus and ketamine (Correspondence). Anaesthesia 1991; 46: 1086

11 Hamza J, Ecoffey C, Gross $J B$. Ventilatory response to $\mathrm{CO}_{2}$ following intravenous ketamine in children. Anesthesiology 1989; 70: 422-5.

12 Lockhart CH, Nelson WL. The relationship of ketamine requirement to age in pediatric patients. Anesthesiology 1974; 40: 507-8.

13 Grant IS, Nimmo WS, McNichol LR, Clements JA. Ketamine disposition in children and adults. $\mathrm{Br} J$ Anaesth 1983; 55: 1107-11. 